\title{
Comparative performance analysis of hybrid differential evolution and pattern search technique for frequency control of the electric power system
}

\author{
Pratap Chandra Pradhan ${ }^{1}$, Rabindra Kumar Sahu ${ }^{2^{*}}$ and Sidhartha Panda ${ }^{3}$
}

\author{
*Correspondence: \\ rksahu_ee@vssut.ac.in \\ ${ }^{2}$ Department of Electrical \\ \& Electronics Engineering, \\ Veer Surendra Sai University \\ of Technology (VSSUT), Burla \\ Odisha 768018, India \\ Full list of author information \\ is available at the end of the \\ article
}

\begin{abstract}
In the current situation, operation and control of power system is a greater challenge. The most significant situation in power system control is load frequency control. In the present work, a hybrid differential evolution and pattern search (hDE-PS) method has been suggested for frequency regulation of electrical power systems. Fractional-order proportional integral derivative (FOPID) controller is implemented for design and analysis purpose. The suggested control method has been applied for two electrical power systems model, i.e., 2-area diverse source power system with/without HVDC linkage and 2-area thermal system. The performances of the suggested controller have been evaluated with PID and optimal controller. The simulation results indicate that system performances are enhanced with the suggested approach for identical structure. Robustness of the suggested approach has been analyzed by variation in random load and the system parameters. The suggested method (hDE-PS tuned FOPID) is further investigated with a 2-area thermal system. The performance of the recommended approach is analyzed by equating the results with other newly available approaches, like Genetic Algorithm (GA), Bacteria Foraging Optimization Algorithm (BFOA), Particle Swarm Optimization (PSO), hybrid BFOA and PSO (hBFOA-PSO), multi-objective Nondominated Sorting Genetic Algorithm (NSGA)-II and Firefly Algorithm for the similar structure.
\end{abstract}

Keywords: Frequency regulation, Hybrid differential evolution and pattern search (hDE-PS), Fractional-order controller, Sensitivity

\section{Introduction}

In today's era of the present power scenario, load frequency control (LFC) is flattering the recent challenge. Due to small deviation in frequency, there will be enlarging the magnetic flux which is lead to raise the magnetizing current. The core of the transformer gets saturated, and the coil could be burned as of severe current $[1,2]$. It is a very difficult task to preserve a steady frequency, to attain a stable function of the power system. For a steady position, the sum of generated power in a system is equal to the total load demand plus losses. As load changes erratically, there will be unbalanced between

(c) The Author(s) 2021. This article is licensed under a Creative Commons Attribution 4.0 International License, which permits use, sharing, adaptation, distribution and reproduction in any medium or format, as long as you give appropriate credit to the original author(s) and the source, provide a link to the Creative Commons licence, and indicate if changes were made. The images or other third party material in this article are included in the article's Creative Commons licence, unless indicated otherwise in a credit line to the material. If material is not included in the article's Creative Commons licence and your intended use is not permitted by statutory regulation or exceeds the permitted use, you will need to obtain permission directly from the copyright holder. To view a copy of this licence, visit http://creativecommons. org/licenses/by/4.0/. 
generation and load. The variance of power directs to alter in generator speed and consequently its frequency. To keep a steady frequency, LFC is used. LFC is being planned to observe the system frequency even as remaining the system strong [3-6].

Many researchers worldwide are building an effort to discover the various control methods and optimization techniques for controlling the frequency. Computational intelligence methods such as Bacteria Foraging Optimization Algorithm (BFOA) [7], Differential Evolution (DE) [8], hybrid BFOA-PSO [9], Multi-objective Non-Dominated Sorting Genetic Algorithm-II [10], Firefly Algorithm (FA) [11], Craziness-based Particle Swarm Optimization (CPSO) [12], Teaching Learning-Based Optimization (TLBO) algorithm [13], Optimal Gravitational Search Algorithm (GSA) [14], Flower Pollination Algorithm (FPA) [15], Grey Wolf Optimization (GWO) [16], Imperialist Competitive Algorithm (ICA) [17], hybrid Stochastic Fractal Search and Local Unimodal Sampling (hSFS-LUS) [18], Adaptive DE [19], hybrid MOL-GSA [20], Whale Optimization Algorithm (WOA) [21], hybrid GSA and PS (hGSA-PS) [22], Modified Moth Swarm Algorithm (MMSA) [23], Modified DE algorithm [24] have been newly proposed for frequency regulation problems.

Literature review illustrates that system performance not only depends on soft computing method but also on the controller construction. Literature survey reveals that the optimal controller [25-27], Classical controllers [28], 2DOF PID controller [29], Sliding mode controllers [30], Tilt integral derivative controller with filter [31], PIDN-FOID [32], fuzzy FOPI-FOPD [33], fuzzy PIDN-FOI [34], Intelligent linear-quadratic optimal output feedback regulator [35], Output feedback control strategy [36] have been proposed. Ibraheem et al. [27] have studied the optimal control theory to realistic system model with/without HVDC link through existing AC connection. The authors have not judged the significant physical limitation, i.e., time delay (TD) in the model which influence the power system performance. Thus to obtain precise insight into the LFC, it is essential to incorporate the vital physical restraints in the model. This needs further comprehensive study with the consideration of TD and random load disturbances.

In recent times, the fractional-order (FO) controller gets potential use in the field of engineering and science [37]. The FOPID is the expansion of the classical PID based on fractional calculus. In FOPID, proportional $\left(K_{\mathrm{P}}\right)$, integral $\left(K_{\mathrm{I}}\right)$, derivative $\left(K_{\mathrm{D}}\right)$ gains, integral order $(\lambda)$ and derivative order $(\mu)$ are as plan terms which offer superior litheness in controller research. Different methods have been exercised in the literature for optimizing FOPID. From several methods, Differential Evolution (DE) algorithm is a universal tuning technique planned to discover the exploration space and chief probable offers an optimal/near-optimal result if applied alone. Further, a local optimizing technique such as PS is considered to develop a local area [38]; however, they are typically not superior at investigating broad region and thus not useful alone for universal tuning. Owing to their benefit and limitation, there is an inspiration for the hybridization of DE and PS. Nevertheless, no effort has been made to develop hybrid DE-PS-tuned optimal/FOPID/ PID controllers for the frequency regulation problem.

It is seen from literature survey that important physical constraints such as time delay (TD) have not been considered in the system model which affect the system performance. Due to the increasing intricacy of power systems in deregulated environment, communication delays become a major challenge in the LFC study. Time delays 
can degrade a system's performance and even cause system instability. Thus to acquire precise insight of the LFC problem, it is essential to hold the vital physical constraints in the system model. This study presents both the usage of a powerful computational intelligence technique like DE and hybrid DE-PS in order to optimize the optimal/PID/ FOPID controller parameters of a LFC system. The advantage of hybrid DE-PS is verified by equating the results with DE-optimized FOPID controller, further, to exhibit the capability of the suggested hDE-PS-optimized FOPID controller to cope with random load disturbances.

Next, the advantage of the suggested method (hDE-PS-optimized FOPID) is verified by equating the results with newly available modern heuristic optimization approaches such as DE [8], BFOA [7], GA [7], PSO [9], hBFOA-PSO [9], NSGA-II [10], FA [11] and conventional Ziegler Nichols (ZN) [7] for a non-reheat two area thermal power systems.

The primary contribution this paper comprises:

a. To propose a hybrid DE-PS technique-based FOPID/PID/optimal output feedback controller for frequency regulation with/without HVDC link for 2-area 6-unit power system.

b. The advantage of the suggested hDE-PS-optimized FOPID is presented by equating the results over conventional PID and optimal controller for the identical structure.

c. Robustness of the suggested method is examined by taking into account the change in parameters and random step load patterns.

d. To exhibit the advantage of hDE-PS-tuned FOID over recently existing technique, i.e., GA [7], BFOA [7], DE [8], hBFOA-PSO [9], NSGA-II [10], FA [11] optimized various controller like PI \&PID for an identical test system.

\section{System design}

In the current paper, two electrical power system models are engaged to examine the ability of the suggested controller for LFC, which are commonly used in the literature. The test system-I presented in Fig. 1 is 2-area 6-unit system with/without HVDC link [24-27]. The system comprises a source like thermal hydro-gas. The test system parameters are taken from reference [27]. The readers are advised to refer [27] for the definition and meaning of symbols used in Fig. 1 . The generation power rating of every area is $2000 \mathrm{MW}$, and nominal loading is $1000 \mathrm{MW}$. The load involvement of thermal, hydro and gas systems is $600 \mathrm{MW}, 250 \mathrm{MW}$ and $150 \mathrm{MW}$, respectively. For more practical power system, time delay (TD) element is incorporated in the test model. In the present paper, the value of TD is taken as $50 \mathrm{~ms}$ [39]. In test system-II, a non-reheat-type thermal system [7-11] is considered as presented in Fig. 2. The detailed data of studied systems are available in [7-11].

\section{Modeling of HVDC linkage}

HVDC link (parallel AC-DC) is connected directly with the AC tie-line interconnected power system for improvement of system performance. The structure of two-area arrangement through AC-DC links is presented in Fig. 3 [24, 25, 27]. The modification of output in area-1 of AC tie and HVDC link is as follows: 


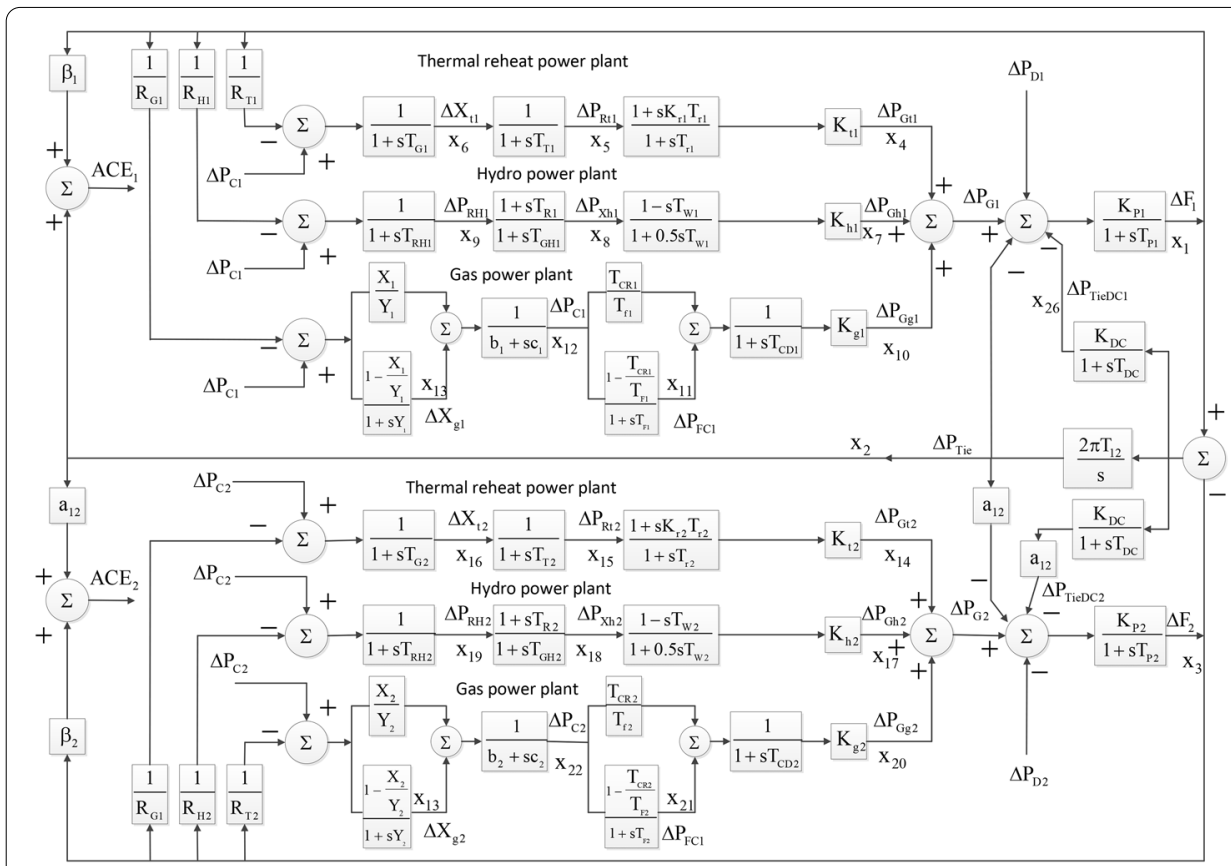

Fig. 1 Two-area multi-source power system (Test system-I)

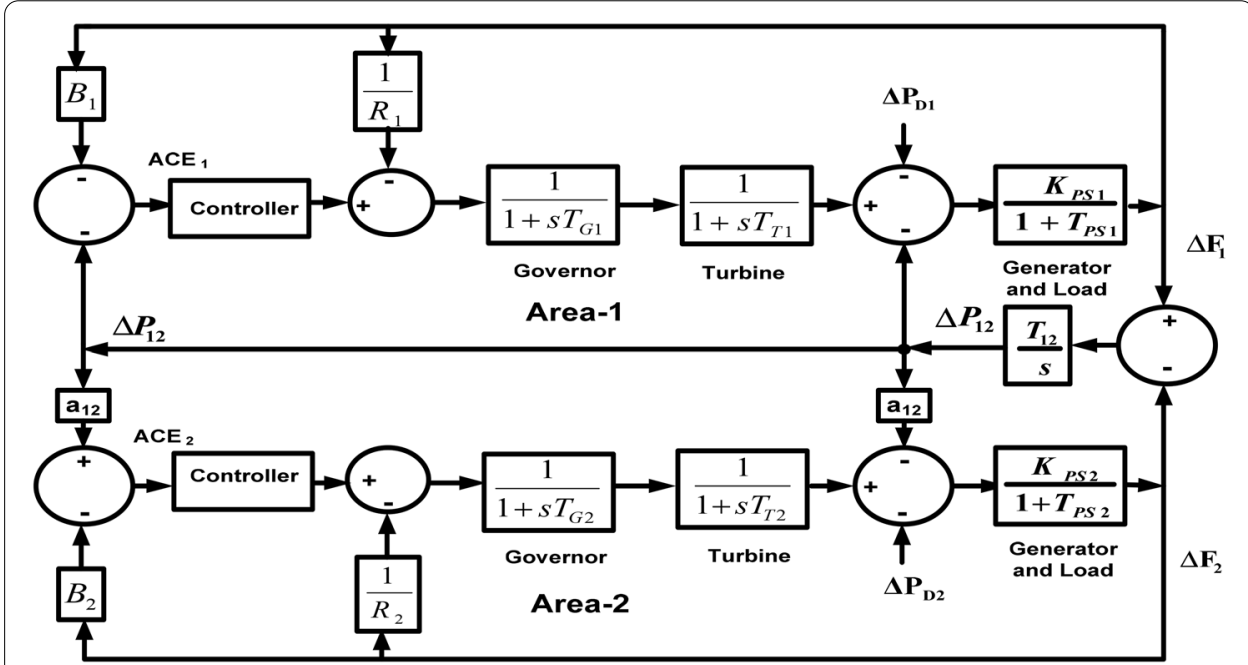

Fig. 2 Non-reheat-type 2-area thermal system (Test system-II)

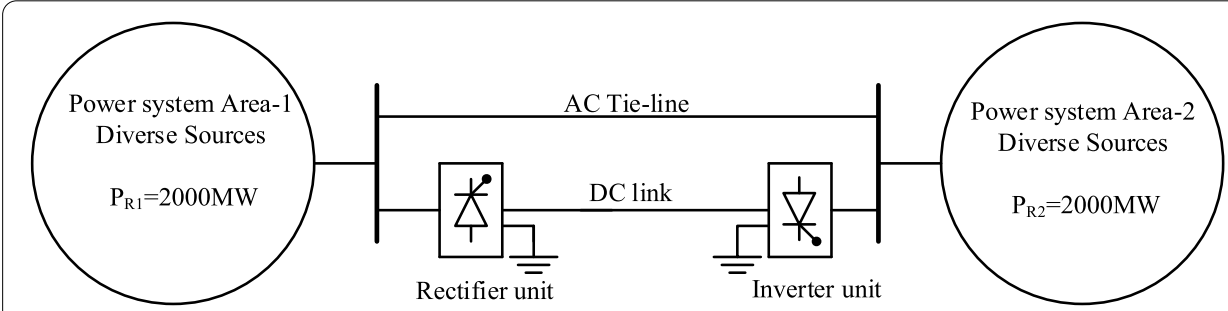

Fig. 3 2-Area system through HVDC link with AC link 


$$
\begin{aligned}
& \Delta P_{\mathrm{AC}}=\frac{2 \pi T_{12}}{s}\left(\Delta F_{1}-\Delta F_{2}\right) \\
& \Delta P_{\mathrm{DC}}=\frac{K_{\mathrm{DC}}}{1+s T_{\mathrm{DC}}}\left(\Delta F_{1}-\Delta F_{2}\right)
\end{aligned}
$$

where $K_{\mathrm{DC}}\left(\mathrm{HVDC}\right.$ link gain) and $T_{\mathrm{DC}}(\mathrm{HVDC}$ link-time constant).

\section{Optimal controller design}

The first step in the development of the design procedure of the controller is the linear representation of the structure. The linear form of the structure is designated in the state space form, as follows:

$$
\dot{\boldsymbol{x}}=\boldsymbol{A} x+\boldsymbol{B} u+\boldsymbol{\Gamma} P_{D}
$$

where $\mathbf{A}\left(n^{*} n\right)$ is state matrix, $\mathbf{B}\left(n^{*} m\right)$ is a control matrix for $n$ number of state variables and $m$ number of inputs, and $\Gamma$ is a disturbance matrix. Different variables have been defined as:

State variables:

$$
\begin{aligned}
& \boldsymbol{x}_{1}=\Delta F_{1}, \boldsymbol{x}_{2}=\Delta P_{\mathrm{Tie}}, \boldsymbol{x}_{3}=\Delta F_{2}, \boldsymbol{x}_{4}=\Delta P_{\mathrm{Gt} 1}, \boldsymbol{x}_{5}=\Delta P_{\mathrm{Rt} 1}, \boldsymbol{x}_{6}=\Delta X_{\mathrm{t} 1}, \boldsymbol{x}_{7}=\Delta P_{\mathrm{Gh} 1}, \boldsymbol{x}_{8}=\Delta X_{\mathrm{h} 1}, \\
& \boldsymbol{x}_{9}=\Delta X_{\mathrm{RH} 1}, \boldsymbol{x}_{10}=\Delta P_{\mathrm{Gg} 1}, \boldsymbol{x}_{11}=\Delta P_{\mathrm{FC} 1}, \boldsymbol{x}_{12}=\Delta P_{\mathrm{VP} 1}, \boldsymbol{x}_{13}=\Delta X_{\mathrm{g} 1}, \boldsymbol{x}_{14}=\Delta P_{\mathrm{Gt} 2}, \boldsymbol{x}_{15}=\Delta P_{\mathrm{Rt} 2}, \\
& \boldsymbol{x}_{16}=\Delta X_{\mathrm{t} 2}, \boldsymbol{x}_{17}=P_{\mathrm{Gh} 2}, \boldsymbol{x}_{18}=\Delta X_{\mathrm{h} 2}, \boldsymbol{x}_{19}=\Delta X_{\mathrm{RH} 2}, \boldsymbol{x}_{20}=\Delta \mathrm{P}_{\mathrm{Gg} 2}, \boldsymbol{x}_{21}=\Delta P_{\mathrm{FC} 2}, \boldsymbol{x}_{22}=\Delta P_{\mathrm{VP} 2}, \\
& \boldsymbol{x}_{23}=\Delta X_{\mathrm{g} 2}, \boldsymbol{x}_{24}=\int A C E_{1}, x_{25}=\int A C E_{2}, \boldsymbol{x}_{26}=\Delta P_{\mathrm{Tie} D C} . \\
& \text { Control inputs: } \\
& u_{1}=\Delta P_{\mathrm{C} 1} ; u_{2}=\Delta P_{\mathrm{C} 2} ; U=\left[u_{1} u_{2}\right]^{T}
\end{aligned}
$$

Disturbance inputs:

$$
\Delta \mathrm{P}_{\mathrm{D} 1} ; \Delta \mathrm{P}_{\mathrm{D} 2} ; \mathbf{P}_{\mathrm{D}}=\left[\Delta \mathrm{P}_{\mathrm{D} 1} \Delta \mathrm{P}_{\mathrm{D} 2}\right]^{\mathrm{T}} \text {. }
$$

The system state variables $\left(\dot{\mathrm{x}_{1}}-\dot{\mathrm{x}_{26}}\right)$ equations concerning transfer function block in Fig. 1 can be expressed from which the input matrices $\mathbf{A}$ are found to be of the order $26 \times 26$, the matrix $B$ is of the order of $26 \times 2$, and the matrix $\Gamma$ is of the order of $26 \times 2$. The output is given by (4).

$$
Y=C X+D U
$$

For matrix ' $\mathbf{D}$ ' is considered as zero.

Therefore, the output is represented as

$$
Y=C X
$$

where ' $\mathbf{C}$ ' matrix is the order of $(2 \times 26)$ describe the output matrix.

The values of matrices can be calculated with the help of [27]. The 26 states are $\boldsymbol{x}_{1}$, $x_{2} \ldots x_{26}$.

Hence, finally, the equation for control input can be written as:

$$
\mathbf{U}=-(\mathbf{K X})
$$

where ' $K$ ' is a $(2 \times 26)$ matrix known as feedback matrix gain and is represented by: 


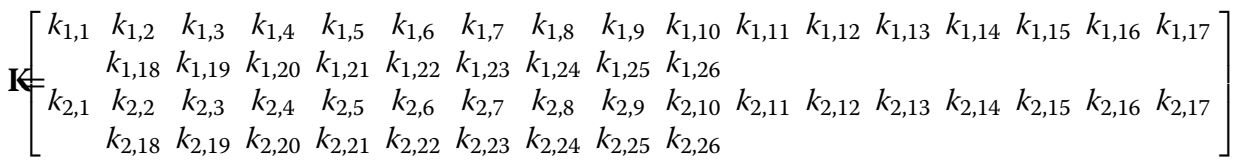

The quadratic form of performance index (PI) is as follows

$$
\mathrm{PI}=\frac{1}{2} \int_{0}^{\infty}\left(x^{T} Q x+u^{T} R u\right) \mathrm{d} t
$$

where 'Q' represents 'State Weighing Matrix' and 'R' represents 'Control Weighing Matrix'

The variation of area control errors (ACE) is:

$$
\begin{aligned}
& e_{1}(t)=A C E_{1}=B_{1} \Delta F_{1}+\Delta P_{T i e 12}=\beta_{1} x_{1}+x_{3} \\
& e_{2}(t)=A C E_{2}=B_{2} \Delta F_{2}+\Delta P_{T i e 21}=\beta_{2} x_{2}-x_{3}
\end{aligned}
$$

The deviations of $\int A C E(\mathrm{~d} t)$ about the steady-state values are minimized. For this case, these deviations are $x_{24}$ and $x_{25}$. The deviations of control inputs $\left(u_{1}\right.$ and $\left.u_{2}\right)$ about the steady-state values are minimized. Based on the realistic control specifications requisite of LFC scheme, it is perceived from literature that the best system performance is acquired with minimum values of settling times, peak overshoots, and maximum value of damping ratio in frequency and tie-line power deviations when ITAE is employed as objective function [22]. Therefore, ITAE is elected as a cost function in the current study to determine the parameters of the controller and given by:

$$
J=\operatorname{ITAE}=\int_{0}^{t}\left(\left|\Delta F_{1}\right|+\left|\Delta F_{2}\right|+\left|\Delta P_{T i e}\right|\right) \cdot t . \mathrm{d} t
$$

For optimal control problem, the objective function is written as:

$$
J=I T A E=\int_{0}^{t_{\text {sim }}}\left(\left|\mathrm{x}_{1}\right|+\left|\mathrm{x}_{2}\right|+\left|\mathrm{x}_{3}\right|\right) \cdot t . d t
$$

\section{State-space model of Test system-II}

The state-space representation of input, control and disturbance vectors for the system under study is:

State vector:

$$
[X]^{T}=\left[\begin{array}{llllll}
\Delta F_{1} & \Delta P_{T i e} \Delta F_{2} & \Delta P_{G t 1} & \Delta P_{R t 1} & \Delta X_{t 1} & \Delta P_{G h 1} \\
\Delta X_{h 1} & \Delta X_{R H 1} & \Delta P_{G g 1} & \Delta P_{F C 1} & \Delta P_{V P 1} & \Delta X_{g 1} \\
\Delta P_{G t 2} & \Delta P_{R t 2} & \Delta X_{t 2} & \Delta P_{G h 2} & \Delta X_{h 2} & \Delta X_{R H 2} \\
\Delta P_{G g 2} & \Delta P_{F C 2} & \Delta P_{V P 2} & \Delta X_{g 2} & \int A C E_{1} \mathrm{~d} t \int A C E_{2} \mathrm{~d} t \\
\Delta P_{T i e D C} & & & &
\end{array}\right]
$$

Control vector: 


$$
\underline{U}=\left[\begin{array}{ll}
\Delta P_{C 1} & \Delta P_{C 2}
\end{array}\right]^{T}
$$

Disturbance vector:

$$
\underline{P_{d}}=\left[\begin{array}{ll}
\Delta P_{D 1} & \Delta P_{D 2}
\end{array}\right]^{T}
$$

The matrices of state space are found by using the equations of state space. The detailed equations of state space are given in reference [27].

\section{FOPID controller}

Conventional PID controllers may not offered required system performance if it is connected with nonlinearity parameters. Extensive development has been noticed in the growth of intelligent controllers applied to different power systems, but still, it remains a demanding area and a general problem for researchers. The fuzzy logicbased controller needs more fuzzy variables for better accuracy. This will exponentially increase the rues. The PID controller has been effectively used in many applications. The acceptance of the PID is due to the ease of the design processes and acceptable performance. The fractional-order controller design methods are in principle founded on additions of the traditional PID control theory, with an importance on the greater flexibility in the tuning approach ensuing improved control performances as related to classical control. Fractional calculus has become very beneficial in recent times because of its applications in many applied sciences. Persuaded from the positive results of these developments, a FOPID structure is suggested for LFC of power system.

FOPID controller has been suggested in the current paper which includes a fractionalorder and PID configuration. Conventional PID controllers are normally not effectual as of their linear arrangement, mainly, if higher-order plants are concerned or if time delay systems and uncertainties are there. On the contrary, the FOPID can handle nonlinearity and uncertainties. The FOPID can be intended to match the necessary performance of the control system. From the literature, it is seen that application of FOPID enhanced the performance of PID/PI. The proposed FOPID controller gets advantages of outstanding ability of a PID in addition to the feedback control mechanism in removing the steady-state error in addition to predicting and controlling future error.

The main advantages of FOPID are that if the parameter of a power system varies, a fractional-order (FO) PID is less responsive over a conventional PID [33, 37]. Additionally, the FO has two additional variables to optimize. Its offers further degrees of freedom to the dynamic properties of FO structure. The FOPID configuration assumed in each generating element is shown in Fig. 4. The inputs to the controllers are the respective ACEs, and outputs of the controllers are the reference power setting of generating units $\Delta P_{c}$. In Fig. $4, K_{P}, K_{I}, K_{D} \lambda$ and $\mu$ are to be optimized. The expression of FOPID is given by Eq. (15).

$$
G(s)=K_{\mathrm{P}}+\frac{K_{\mathrm{I}}}{S_{\lambda}}+K_{\mathrm{D}} S^{\mu}
$$




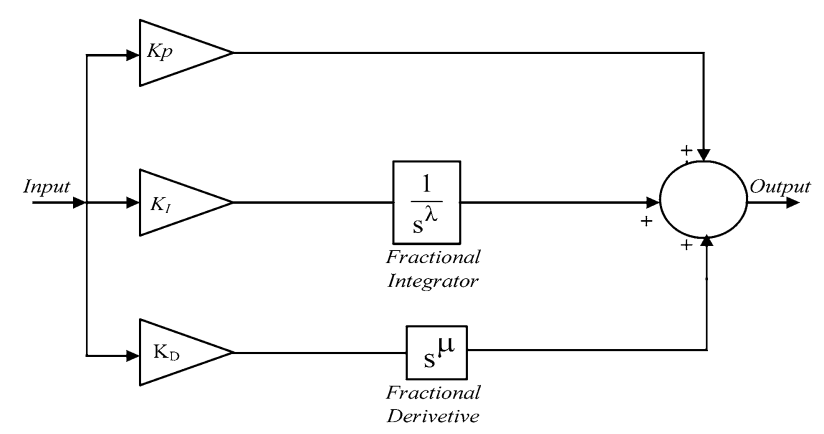

Fig. 4 Structure of FOPID controller

\section{Outline of hybrid Differential Evolution and Pattern Search (hDE-PS) method}

Finding a global optimal solution is a difficult assignment in several applications due to the fact that data and models are generally nonlinear and subject to diverse sources of error. By the way, hybrid optimization algorithms have achieved attractiveness as it has become apparent that there cannot be a universal optimization strategy which is globally more beneficial than any other. In the current work, an effort has been prepared to apply a hybrid DE method and PS technique to tune the controller parameters.

In this method, DE is utilized for overall exploration \& the Pattern Search technique [38] engaged for local search. The initial stage is explorative, using a conventional DE to recognize capable regions of the explore space. The superb result set up by $\mathrm{DE}$ is subsequently refined with PS technique through a succeeding exploitative stage. To set up the advantage of suggested hDE-PS method, the results are evaluated by the individual DE method.

Differential Evolution (DE) technique is a straightforward, capable, but effective technique and applied to numerous design problems [40]. It gives remarkable performance for dynamic, multi-objective, constraint problems. Four main steps of differential evaluation are, namely initialization, mutation, crossover and selection. Boot starts with creating an initial population vector of $N_{P}$. The initial population is proposed to give rise to consecutive generations. Selection of the initial population is made initial arbitrarily. For each generation entities of the existing population are called target vector. Beginning step toward generating new solutions is called a mutation. The crossover of the population is done, which is resultant from mutation and the original population, where a recent vector known as the anticipated vector is created. $C_{R}$ as the crossover factor is a constant value between 0 and 1 . If the normal vector attains better fitness rates that of target vector, it substitutes the target vector in the successive generation. The recent population is substituted by the new population, and a new loop will be generated. Some fundamental issues need to be determined for the implementation of DE. They are initialization, DE scaling factor $(f)$, crossover probability $\left(C_{R}\right)$ and population size $\left(N_{P}\right)$. The range of scaling factor is $(0,2)$. Amount of perturbation is controlled by this range in the process of mutation. Crossover probability $\left(C_{R}\right)$ is usually selected between the interval $(0,2)$. The DE technique is described in [8] in a detailed manner.

The PS method is an easy concept, simple to realize and computationally competent $[22,38]$. The PS method calculates a series of spots that could or could not come up 
to the finest position. The method initiates by a set of positions named mesh, about the original positions. The original positions or present positions are offered through the DE method. The mesh is formed by accumulation the present positions to a scalar several of a set of vectors named a pattern. However, a position in the network is having superior error value, and it becomes the present position next to iteration. The detail about the PS technique is available in the literature [22].

\section{Results and discussion}

\section{2-Area diverse source system (Test system-I)}

Simulation of test system-I, which is a 2-area multi-source system with/without HVDC link exhibited in Fig. 1 [24-27], is done using FOPID/PID/Optimal output feedback controller. Each area includes hydro, gas and thermal generation units. The test system is performed with a sudden rise in a load of $1 \%$ in area-1 $\left(\Delta P_{D 1}=0.01\right.$ p.u.MW $)$ at $t=0 \mathrm{~s}$ in the first area, and optimized controller parameters are obtained with the DE/hDE-PS techniques. Tables 1 and 2 provide optimal gains and PID/FOPID controller for (1) AC link and (2) parallel AC/DC links, respectively. For comparison, the results of other controllers like optimal and PID controller are also considered. For identical power structure, the lowest error value is acquired by DE optimized FOPID (ITAE $=0.8723$ ) equated to PID $(\mathrm{ITAE}=2.7718)$ and optimal $(\mathrm{ITAE}=9.3341)$ controller which is observable from Table 3. It is noticed that the ITAE value with FOPID is reduced by $90.65 \%$ and $68.53 \%$ compared to optimal and PID, respectively. DE based FOPID shows minimal settling times $\left(\mathrm{T}_{\mathrm{S}}\right)(23.03,23.09,13.21)$, peak overshoot $\left(\mathrm{O}_{\mathrm{S}}\right) 10^{-3} \mathrm{x}(3.2,4.1,3.7)$ and peak undershoot $\left(\mathrm{U}_{\mathrm{S}}\right) 10^{-3} \mathrm{x}(-16.0,-20.8,-0.2)$ values compared to optimal controller $\mathrm{Ts}(64.9$, $64.9,42.9), \mathrm{O}_{\mathrm{S}} 10^{-3} \mathrm{x}(13.2,11.3,6.2), \mathrm{U}_{\mathrm{S}} 10^{-3} \mathrm{x}(-57.9,-44.8,-8.60)$ and PID controller Ts $(46.34,46.34,39.89), \mathrm{O}_{\mathrm{S}} 10^{-3} \mathrm{x}(22.6,28.3,5.5), \mathrm{U}_{\mathrm{S}} 10^{-3} \mathrm{x}(-28.4,-31.1,-3.20)$ as specified in Table 3. This exhibits the advantage of the suggested FOPID over PID and optimal controller.

It is also clear from Table 3 that with the application of suggested technique (hDEPS), the error value is further reduced (ITAE $=0.6452$ ). The ITAE value with $\mathrm{hDE}$-PS is reduced by $35.20 \%$ compared to DE. Also, hDE-PS offers better results compared to DE with Ts $(12.65,10.84,11.20), \mathrm{O}_{\mathrm{S}} 10^{-3} \mathrm{x}(1.0,1.8,3.6)$ and $\mathrm{U}_{\mathrm{S}} 10^{-3} \mathrm{x}(-16.0,-20.9,-0.10)$. It is useful to state at this point that in the above assessment, same model, controller (FOPID) and ITAE objective function are considered. It can be concluded suggested hDE-PS approach offers improved result equated to DE method as minimum error value is attained. Least settling times, $\mathrm{O}_{\mathrm{S}}$ and $\mathrm{U}_{\mathrm{S}}$ in $\Delta F$ and $\Delta P_{T i e}$, are also obtained with a suggested approach compared to others.

The transient response of systems is presented in Fig. $5 \mathrm{a}-\mathrm{c}$ for $\Delta P_{D 1}=0.01$ p.u.MW at $\mathrm{t}=0 \mathrm{~s}$. For evaluation, the results with suggested approach (hDE-PS: FOPID controller), DE-optimized FOPID, PID and optimal controllers are also presented in Fig. 5a-c. Since the diverse generations are associated with a rigid network in each area, the frequency variations in an area remain the same in that area. Considerable enhancement is observed through the suggested approach over to other approaches.

To exhibit the efficacy of the suggested approach (hDE-PS: FOPID), simultaneously load disturbances are considered $\left(\Delta P_{D 1}=0.01\right.$ p.u.MW \& $\left.\Delta P_{D 2}=0.02 p . u . M W\right)$. In this case, a sudden rise in a load of $1 \%$ is applied in area- $1 \& 2 \%$ in area- 2 . The system 
Table 1 Tuned optimal feedback gain matrix

\begin{tabular}{|c|c|c|}
\hline Parameters & AC link & $\begin{array}{l}\text { Parallel } \\
\text { AC-DC link }\end{array}$ \\
\hline$k_{1}$ & 1.7425 & 1.5306 \\
\hline $\mathrm{k}_{2}$ & 0.8997 & 0.7112 \\
\hline$k_{3}$ & -1.3349 & 1.4300 \\
\hline $\mathrm{k}_{4}$ & 0.6772 & 1.8931 \\
\hline$k_{5}$ & 1.3603 & 1.2474 \\
\hline$k_{6}$ & 0.1406 & -0.0329 \\
\hline $\mathrm{k}_{7}$ & 0.0243 & -0.2212 \\
\hline$k_{8}$ & -0.9005 & -0.9479 \\
\hline$k_{9}$ & 0.5440 & 0.2004 \\
\hline $\mathrm{k}_{10}$ & 1.5463 & 0.2844 \\
\hline $\mathrm{k}_{11}$ & 1.1735 & 1.5962 \\
\hline$k_{12}$ & -0.1054 & -1.2368 \\
\hline$k_{13}$ & -0.5692 & -0.0252 \\
\hline $\mathrm{k}_{14}$ & -1.5034 & -1.0056 \\
\hline $\mathrm{k}_{15}$ & 0.3134 & 0.3920 \\
\hline$k_{16}$ & -1.0508 & -0.5066 \\
\hline$k_{17}$ & 1.6948 & 1.5894 \\
\hline $\mathrm{k}_{18}$ & -1.0446 & 0.5825 \\
\hline $\mathrm{k}_{19}$ & 0.4983 & 0.7403 \\
\hline $\mathrm{k}_{20}$ & 0.2930 & -0.0536 \\
\hline$k_{21}$ & 0.6421 & -0.3179 \\
\hline$k_{22}$ & 0.8966 & 1.7010 \\
\hline$k_{23}$ & 1.4084 & 1.3353 \\
\hline$k_{24}$ & 1.4433 & 1.6641 \\
\hline $\mathrm{k}_{25}$ & -1.3349 & 1.6123 \\
\hline $\mathrm{k}_{26}$ & 0.5298 & -0.5948 \\
\hline $\mathrm{k}_{27}$ & 1.3752 & 1.3408 \\
\hline $\mathrm{k}_{28}$ & 1.7641 & -0.8479 \\
\hline$k_{29}$ & -1.6571 & 0.4305 \\
\hline$k_{30}$ & -0.2549 & 1.2438 \\
\hline$k_{31}$ & -0.0814 & 1.5311 \\
\hline$k_{32}$ & -0.1054 & -0.2312 \\
\hline$k_{33}$ & 1.7671 & -1.6034 \\
\hline$k_{34}$ & -1.9620 & 1.8589 \\
\hline$k_{35}$ & -0.9183 & -0.1582 \\
\hline$k_{36}$ & 0.2028 & 0.8394 \\
\hline$k_{37}$ & -0.8069 & 0.7098 \\
\hline$k_{38}$ & -1.1730 & 1.5235 \\
\hline$k_{39}$ & -0.6833 & 0.2110 \\
\hline$k_{40}$ & -0.6495 & 1.8823 \\
\hline$k_{41}$ & 1.8709 & 0.1306 \\
\hline$k_{42}$ & -1.7750 & 0.4185 \\
\hline$k_{43}$ & 0.6299 & 0.8831 \\
\hline$k_{44}$ & -0.3081 & -0.0963 \\
\hline$k_{45}$ & -1.3550 & -0.5471 \\
\hline$k_{46}$ & 0.8986 & -1.1000 \\
\hline$k_{47}$ & 0.9808 & 1.9733 \\
\hline$k_{48}$ & -1.0999 & 1.9809 \\
\hline$k_{49}$ & 0.3550 & -0.8130 \\
\hline
\end{tabular}


Table 1 (continued)

\begin{tabular}{llr}
\hline Parameters & AC link & Parallel \\
\hline$k_{50}$ & & AC-DC link \\
$k_{51}$ & 1.8766 & -1.9384 \\
$k_{52}$ & - & 0.5359 \\
\hline
\end{tabular}

Table 2 Optimized PID/FOPID controller

\begin{tabular}{|c|c|c|c|c|c|c|}
\hline \multirow[t]{2}{*}{ Gains } & \multicolumn{3}{|l|}{ AC link } & \multicolumn{3}{|c|}{ Parallel AC-DC link } \\
\hline & DE:PID & DE:FOPID & hDE-PS:FOPID & PID & FOPID & hDE-PS:FOPID \\
\hline$K_{p 1}$ & -0.3968 & -1.4056 & -1.5207 & -1.6106 & -1.9956 & -1.9353 \\
\hline$K_{P 2}$ & -1.3719 & 0.6266 & 0.7151 & -1.6106 & 0.8880 & 0.5400 \\
\hline$K_{P 3}$ & -1.0413 & 0.5321 & 0.5485 & -1.7589 & -1.5540 & 1.2598 \\
\hline$K_{11}$ & -0.5039 & -1.5322 & -1.5974 & -1.1799 & -0.0381 & -1.9478 \\
\hline$K_{12}$ & -0.6308 & -1.6221 & -1.6299 & 1.5177 & -1.8206 & -1.7133 \\
\hline$K_{13}$ & -1.0121 & -1.6514 & -1.7125 & -0.6086 & -0.1188 & -1.0104 \\
\hline$K_{D 1}$ & -0.9209 & -1.6221 & -1.5017 & -0.2533 & -1.8206 & -1.5401 \\
\hline$K_{D 2}$ & -1.0952 & -1.1721 & -1.1193 & -1.4752 & -0.3613 & -0.0660 \\
\hline$K_{D 3}$ & -1.8923 & 1.8160 & 1.7229 & 0.6136 & 0.4604 & -0.3920 \\
\hline$\lambda_{1}$ & - & 0.0145 & 0.0201 & - & 0.9227 & 0.3294 \\
\hline$\lambda_{2}$ & - & 0.9426 & 0.9456 & - & 0.7883 & 0.8545 \\
\hline$\lambda_{3}$ & - & 0.0299 & 0.0440 & - & 0.9693 & 0.4782 \\
\hline$\mu_{1}$ & - & 0.9681 & 0.7557 & - & 0.1812 & 0.2327 \\
\hline$\mu_{2}$ & - & 0.2841 & 0.3846 & - & 0.0367 & 0.0410 \\
\hline$\mu_{3}$ & - & 0.5121 & 0.3166 & - & 0.0759 & 0.2442 \\
\hline
\end{tabular}

Table 3 Comparative performance index values under different cases

\begin{tabular}{|c|c|c|c|c|c|c|c|c|c|}
\hline \multirow[t]{2}{*}{ Parameters } & & \multicolumn{4}{|l|}{ AC link } & \multicolumn{4}{|c|}{ Parallel AC-DC link } \\
\hline & & $\begin{array}{l}\text { DE: } \\
\text { Optimal }\end{array}$ & $\begin{array}{l}\text { DE: } \\
\text { PID }\end{array}$ & $\begin{array}{l}\text { DE: } \\
\text { FOPID }\end{array}$ & $\begin{array}{l}\text { hDE-PS: } \\
\text { FOPID }\end{array}$ & $\begin{array}{l}\text { DE: } \\
\text { Optimal }\end{array}$ & $\begin{array}{l}\text { DE: } \\
\text { PID }\end{array}$ & $\begin{array}{l}\text { DE: } \\
\text { FOPID }\end{array}$ & $\begin{array}{l}\text { hDE-PS: } \\
\text { FOPID }\end{array}$ \\
\hline ITAE & & 9.3341 & 2.7718 & 0.8723 & 0.6452 & 5.6170 & 0.9906 & 0.3738 & 0.2156 \\
\hline \multirow[t]{3}{*}{$\mathrm{T}_{\mathrm{S}}(\mathrm{s})$} & $\Delta \mathrm{F}_{1}$ & 64.90 & 46.34 & 23.03 & 12.65 & 33.36 & 24.02 & 6.04 & 3.72 \\
\hline & $\Delta \mathrm{F}_{2}$ & 64.90 & 46.34 & 23.09 & 10.84 & 35.36 & 26.21 & 4.66 & 4.03 \\
\hline & $\Delta \mathrm{P}_{\mathrm{Tie}}$ & 42.90 & 39.89 & 13.21 & 11.20 & 38.82 & 30.63 & 8.74 & 5.79 \\
\hline \multirow[t]{3}{*}{ Peak over shoot $\left(\times 10^{-3}\right)$} & $\Delta \mathrm{F}_{1}$ & 13.2 & 22.6 & 3.2 & 1.0 & 8.7 & 7.5 & 2.4 & 0.5 \\
\hline & $\Delta \mathrm{F}_{2}$ & 11.3 & 28.3 & 4.1 & 1.8 & 15.0 & 8.0 & 2.7 & 1.1 \\
\hline & $\Delta \mathrm{P}_{\mathrm{Tie}}$ & 6.2 & 5.5 & 3.7 & 3.6 & 15.0 & 2.0 & 0.3 & 1.2 \\
\hline \multirow[t]{3}{*}{ Peak under shoot $\left(\times 10^{-3}\right)$} & $\Delta \mathrm{F}_{1}$ & -57.9 & -28.4 & -16.0 & -16.0 & -27.2 & -20.7 & -18.7 & -12.0 \\
\hline & $\Delta \mathrm{F}_{2}$ & -44.8 & -31.1 & -20.8 & -20.9 & -40.5 & -24.9 & -15.9 & -13.3 \\
\hline & $\Delta \mathrm{P}_{\mathrm{Tie}}$ & -8.60 & -3.20 & -0.20 & -0.10 & -1.10 & -1.30 & -1.50 & -0.2 \\
\hline
\end{tabular}

responses for the suggested approach and other methods are displayed in Fig. 5d-f. It is noticeable from Fig. $5 \mathrm{~d}-\mathrm{f}$ that the recommended controller illustrates significantly improved performance than the other approaches. Hence, the designed hDE-PS: FOPID controllers are robust and it acts reasonably regardless of the position of disturbance. 


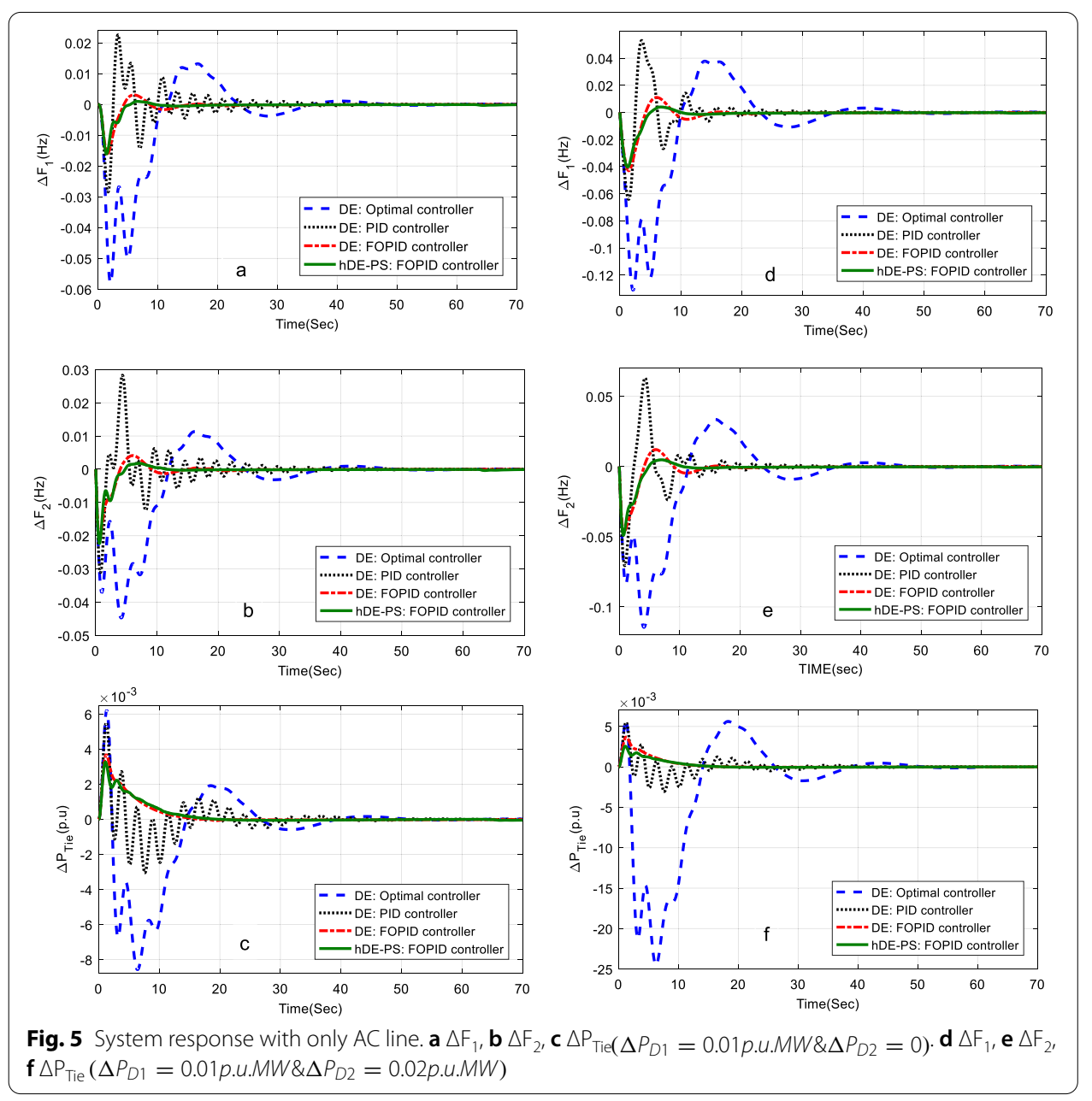

\section{Extension to 2-area diverse source system through parallel AC/DC linkages}

To exhibit the capability of the suggested technique the work is additionally comprehensive to a 2-area multi-source system through parallel AC/DC links which is presented in Fig. 3 [24, 25, 27]. The representation of the test system is displayed in Fig. 1 . The test system is carried out with a sudden rise in a load of $1 \%$ used in area-1 $\left(\Delta P_{D 1}=0.01\right.$ p.u.MW $)$ at $\mathrm{t}=0 \mathrm{~s}$, and optimized controller parameters with HVDC link utilizing ITAE objective function are available in Table 2 . The system performance solutions are given in Table 3.

It can be observed from Table 3 that less ITAE value (0.3738) is found with DE: FOPID compared to ITAE value obtained with DE: optimal (5.6170) and DE: PID (0.9906). It is apprehended that the ITAE value is decreased by $93.35 \%$ and $62.27 \%$ with optimal and PID controller, respectively. DE: FOPID illustrates smallest $\mathrm{T}_{\mathrm{S}}(6.04,4.66,8.74), \mathrm{O}_{\mathrm{S}}$ $10^{-3} \mathrm{x}(2.4,2.7,0.3)$ and $\mathrm{U}_{\mathrm{S}} 10^{-3} \mathrm{x}(-18.7,-15.9,-1.50)$ values compared to optimal controller Ts $(33.36,35.36,38.82), \mathrm{O}_{\mathrm{S}} 10^{-3} \mathrm{x}(8.7,15,15), \mathrm{U}_{\mathrm{S}} 10^{-3} \mathrm{x}(-27.2,-40.5,-1.10)$ and PID controller Ts $(24.02,26.21,30.63), \mathrm{O}_{\mathrm{S}} 10^{-3} \mathrm{x}(7.5,8,2), \mathrm{U}_{\mathrm{S}} 10^{-3} \mathrm{x}(-20.7,-24.9$, -1.30 ) as detailed in Table 3. Further the error value is less (ITAE $=0.2156)$ with hDEPS: FOPID. The ITAE value is decreased by $42.32 \%$ with suggested hDE-PS technique compared to DE. 
Further, it is noticeable from Table 3 that the settling times (3.72, 4.03 and 5.79) are less with HVDC link compared to with AC line only (12.65, 10.84 and 11.20). hDEPS: FOPID with HVDC link shows minimal peak overshoot $\left(\mathrm{O}_{\mathrm{S}}\right) 10^{-3} \mathrm{x}(0.5,1.1,1.2)$ and peak undershoot $\left(\mathrm{U}_{\mathrm{S}}\right) 10^{-3} \mathrm{x}(-12.0,-13.3,-0.2)$ values compared to hDE-PS: FOPID without HVDC link $\mathrm{O}_{\mathrm{S}} 10^{-3} \mathrm{x}(1.0,1.8,3.6)$ and $\mathrm{U}_{\mathrm{S}} 10^{-3} \mathrm{x}(-16.0,--20.9,-0.10)$ as specified in Table 3. This shows the supremacy of the HVDC link. The transient response of the suggested approach (hDE-PS: FOPID) is shown in Fig. 6a-c) with HVDC $\operatorname{link}\left(\Delta P_{D 1}=0.01\right.$ p.u.MW). For a better illustration of results, the transient response obtained by DE-based optimal/PID/FOPID controller is offered in Fig. 6a-c. It is seen from Fig. $6 \mathrm{a}-\mathrm{c}$ that the result of the suggested method is better in terms of $\mathrm{T}_{S}, \mathrm{O}_{\mathrm{S}}$ and $\mathrm{U}_{\mathrm{S}}$ than other methods. To show the strength of the suggested method, simultaneously load disturbances $\left(\Delta P_{D 1}=0.01\right.$ p.u.MW $\& \Delta P_{D 2}=0.02$ p.u.MW $)$ are considered. The system responses are exposed in Fig. $6 \mathrm{~d}-\mathrm{f}$ from which it is obvious that the FOPID controller is strong and execute satisfactorily for different location and size of the disturbance variation. The dynamics of all the energy sources in the areas are presented in Fig. 7a-c. The contribution of each generation source following a load disturbance is shown in Fig. 7.

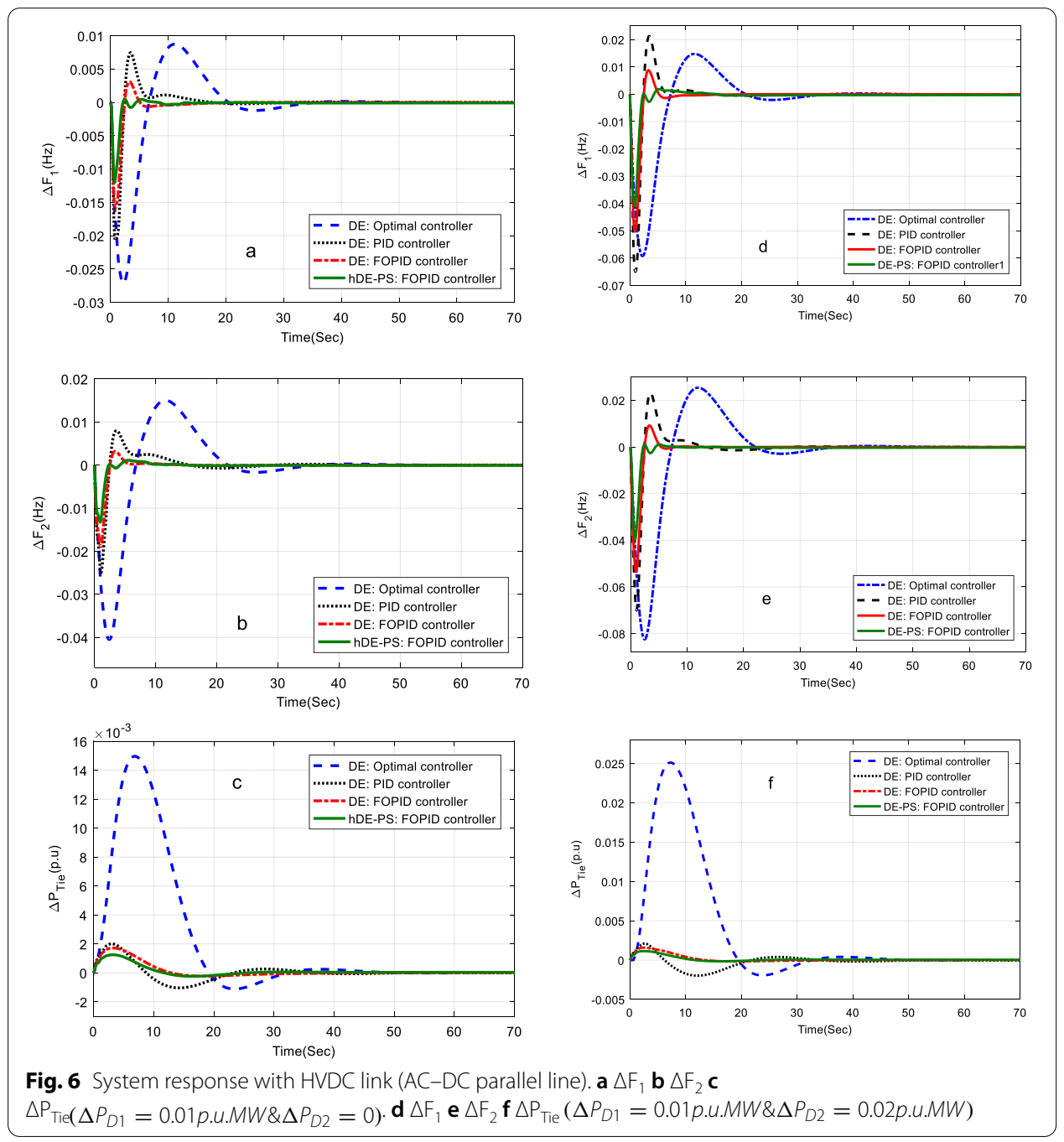



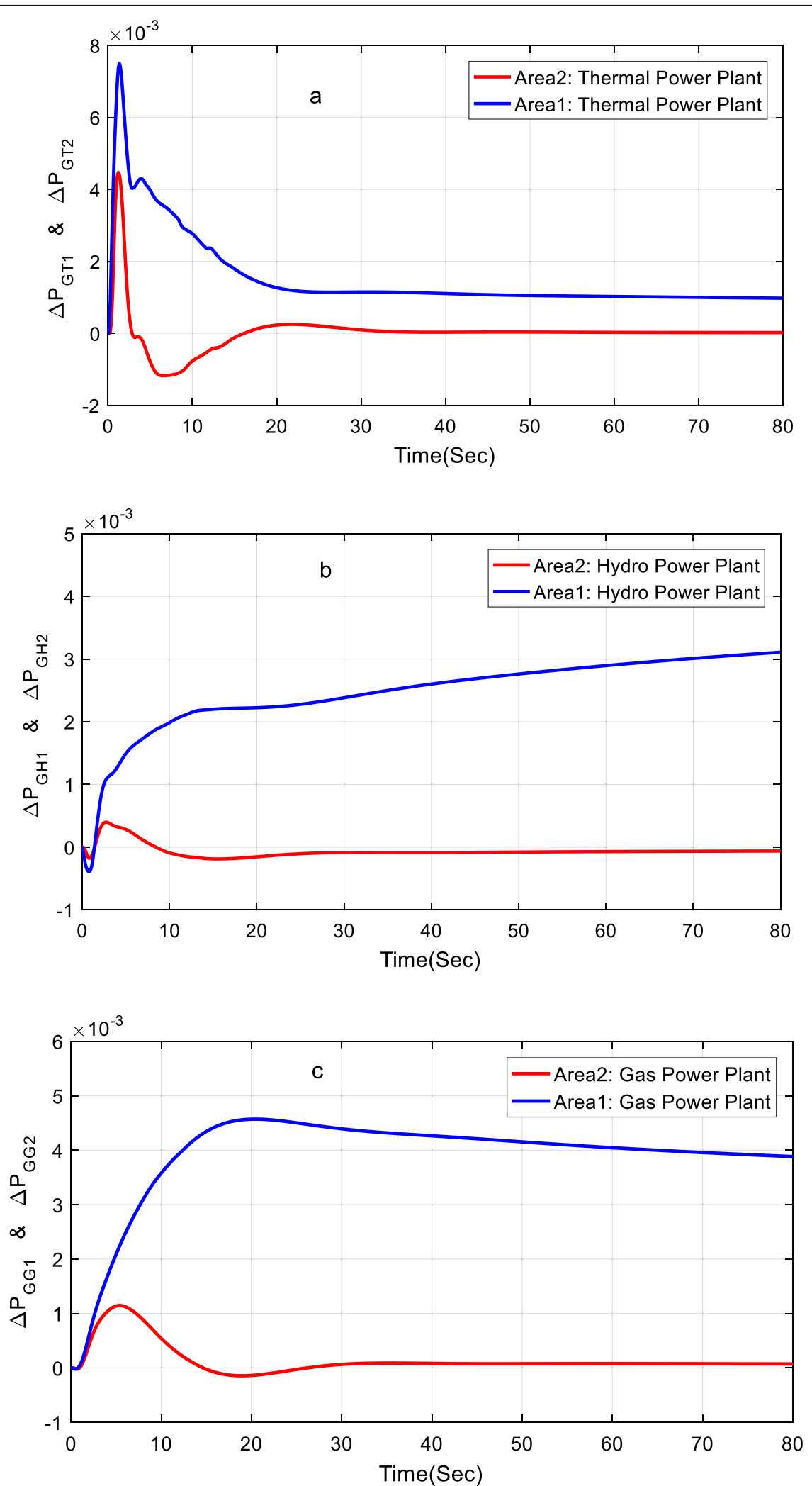

Fig. 7 System response $\left(\Delta P_{D 1}=0.01\right.$ p.u.MW\& $\left.\Delta P_{D 2}=0\right)$ with HVDC link. a Deviation in generated powers in thermal power plant. $\mathbf{b}$ Change in generated powers in hydro power plant. $\mathbf{c}$ Change in generated powers in gas power plant 
It is worthwhile to mention here that as per the requirement of LFC scheme, under normal operating conditions, each area should carry its own load and the power exchange between control areas following a load perturbation should be maintained at its prescheduled value as quickly as possible. It is clear from Fig. 7 that when a load disturbance is applied in area -1 , all the plants in area- 1 increase their generation to meet the load demand. To minimize the frequency deviations following a load disturbance in area-1, all the plants in area-2 supply the power during the transient phases only.

\section{Sensitivity study}

The robustness of the recommended method (hDE-PS: FOPID; with HVDC link) is tested with a variation of $\pm 25 \%$ in system parameters [8-11]. The tuned parameters under different circumstances the recommended method (hDE-PS: FOPID; with HVDC link) are shown in Tables 4 and 5. It can be verified from Table 6 that settling time $\left(\mathrm{T}_{\mathrm{S}}\right)$, peak overshoot (Os)/ undershoot(Us) and ITAE values differ within suitable ranges and are close to the values with nominal values. For example, the change in the frequency of area-1 with a deviation of loading is publicized in Fig. 8. From Fig. 8 and Table 6, it can be established that suggested method (hDE-PS: FOPID; with HVDC link) is robust under varied in system parameters. Hence, it proved the strength of the recommended approach.

To examine the advantage of the suggested method (hDE-PS: FOPID; with HVDC link) a random pattern load is considered to area-1. Figure 9a displays the random pattern load [19]. The size and period of the step load are arbitrary. The response for random load pattern with proposed approach is exposed in Fig. 9b-d. The suggested hybrid DE-PS-optimized FOPID controller shows better transient responses than DE-optimized FOPID controller which can be noticed from Fig. 9b-d. The comparative study validates that the suggested hDE-PS-tuned FOPID controller improves system performs

Table 4 Tuned parameters with loading, $T_{G}$ and $T_{T}$ conditions

\begin{tabular}{|c|c|c|c|c|c|c|}
\hline \multirow{2}{*}{$\begin{array}{l}\text { Controller } \\
\text { parameters }\end{array}$} & \multicolumn{2}{|l|}{ Loading } & \multicolumn{2}{|l|}{$\mathrm{T}_{\mathrm{G}}$} & \multicolumn{2}{|l|}{$\mathrm{T}_{\mathrm{T}}$} \\
\hline & $+25 \%$ & $-25 \%$ & $+25 \%$ & $-25 \%$ & $+25 \%$ & $-25 \%$ \\
\hline$K_{P 1}$ & -1.9376 & -1.9330 & -1.9353 & -1.9359 & -1.9379 & -1.9348 \\
\hline$K_{p 2}$ & 0.5390 & 0.5407 & 0.5401 & 0.5402 & 0.5404 & 0.5387 \\
\hline$K_{P 3}$ & -1.2571 & -1.2587 & -1.2592 & -1.2596 & -1.2582 & -1.2593 \\
\hline$K_{11}$ & -1.9465 & -1.9453 & -1.9474 & -1.9472 & -1.9431 & -1.9432 \\
\hline$K_{12}$ & -1.7111 & -1.7121 & -1.7135 & -1.7131 & -1.7121 & -1.7124 \\
\hline$K_{13}$ & -1.0105 & -1.0103 & -1.0106 & -1.0106 & -1.0108 & -1.0102 \\
\hline$K_{D 1}$ & -1.5404 & -1.5396 & -1.5408 & -1.5405 & -1.5395 & -1.5398 \\
\hline$K_{D 2}$ & -0.0663 & -0.0688 & -0.0660 & -0.0660 & -0.0654 & -0.0650 \\
\hline$K_{D 3}$ & -0.3952 & -0.3967 & -0.3920 & -0.3911 & -0.3923 & -0.3935 \\
\hline$\lambda_{1}$ & 0.3275 & 0.3260 & 0.3296 & 0.3297 & 0.3297 & 0.3292 \\
\hline$\lambda_{2}$ & 0.8567 & 0.8535 & 0.8559 & 0.8547 & 0.8567 & 0.8542 \\
\hline$\lambda_{3}$ & 0.4773 & 0.4723 & 0.4776 & 0.4783 & 0.4750 & 0.4725 \\
\hline$\mu_{1}$ & 0.2319 & 0.2329 & 0.2334 & 0.2328 & 0.2324 & 0.2337 \\
\hline$\mu_{2}$ & 0.0442 & 0.0459 & 0.0406 & 0.0417 & 0.0405 & 0.0459 \\
\hline$\mu_{3}$ & 0.2455 & 0.2424 & 0.2443 & 0.2440 & 0.2465 & 0.2445 \\
\hline
\end{tabular}


Table 5 Tuned parameters with $\mathrm{T}_{\mathrm{RH}}, \mathrm{T}_{\mathrm{CD}}$ and $\mathrm{T}_{12}$ conditions

\begin{tabular}{|c|c|c|c|c|c|c|}
\hline \multirow{2}{*}{$\begin{array}{l}\text { Controller } \\
\text { parameters }\end{array}$} & \multicolumn{2}{|l|}{$\mathrm{T}_{\mathrm{RH}}$} & \multicolumn{2}{|l|}{$T_{C D}$} & \multicolumn{2}{|l|}{$\mathrm{T}_{12}$} \\
\hline & $+25 \%$ & $-25 \%$ & $+25 \%$ & $-25 \%$ & $+25 \%$ & $-25 \%$ \\
\hline$K_{P 1}$ & -1.9376 & -1.9317 & -1.9347 & -1.9336 & -1.9315 & -1.9325 \\
\hline$K_{P 2}$ & 0.5383 & 0.5388 & 0.5393 & 0.5400 & 0.5396 & 0.5384 \\
\hline$K_{P 3}$ & -1.2565 & -1.2566 & -1.2578 & -1.2577 & -1.2573 & -1.2568 \\
\hline$K_{11}$ & -1.9430 & -1.9437 & -1.9466 & -1.9470 & -1.9431 & -1.9429 \\
\hline$K_{12}$ & -1.7133 & -1.7136 & -1.7129 & -1.7156 & -1.7123 & -1.7121 \\
\hline$K_{13}$ & -1.0108 & -1.0105 & -1.0107 & -1.0102 & -1.0108 & -1.0101 \\
\hline$K_{D 1}$ & -1.5406 & -1.5401 & -1.5402 & -1.5407 & -1.5404 & -1.5404 \\
\hline$K_{D 2}$ & -0.0620 & -0.0685 & -0.0618 & -0.0694 & -0.0652 & -0.0638 \\
\hline$K_{D 3}$ & -0.3942 & -0.3951 & -0.3924 & -0.3951 & -0.3983 & -0.3953 \\
\hline$\lambda_{1}$ & 0.3257 & 0.3294 & 0.3274 & 0.3289 & 0.3219 & 0.3272 \\
\hline$\lambda_{2}$ & 0.8543 & 0.8561 & 0.8548 & 0.8557 & 0.8570 & 0.8550 \\
\hline$\lambda_{3}$ & 0.4763 & 0.4787 & 0.4722 & 0.4722 & 0.4769 & 0.4753 \\
\hline$\mu_{1}$ & 0.2329 & 0.2317 & 0.2320 & 0.2316 & 0.2327 & 0.2323 \\
\hline$\mu_{2}$ & 0.0418 & 0.0441 & 0.0437 & 0.0425 & 0.0412 & 0.0408 \\
\hline$\mu_{3}$ & 0.2445 & 0.2433 & 0.2425 & 0.2470 & 0.2458 & 0.2449 \\
\hline
\end{tabular}

Table 6 Sensitivity analysis with proposed hybrid DE-PS optimized FOPID controller in parallel AC-DC link

\begin{tabular}{|c|c|c|c|c|c|c|c|c|c|c|c|}
\hline \multirow[t]{2}{*}{$\begin{array}{l}\text { Parameters } \\
\text { variations }\end{array}$} & \multirow[t]{2}{*}{$\%$ change } & \multicolumn{3}{|c|}{ Ts ( $2 \%$ band) } & \multicolumn{3}{|c|}{$\begin{array}{l}\text { Peak overshoot } \\
\left(\times 10^{-3}\right)\end{array}$} & \multicolumn{3}{|c|}{ Peak undershoot $\left(\times 10^{-3}\right)$} & \multirow[t]{2}{*}{ ITAE } \\
\hline & & $\Delta F_{1}$ & $\Delta F_{2}$ & $\Delta \mathrm{P}_{\mathrm{Tie}}$ & $\Delta F_{1}$ & $\Delta F_{2}$ & $\Delta \mathrm{P}_{\mathrm{Tie}}$ & $\Delta \mathrm{F}_{1}$ & $\Delta F_{2}$ & $\Delta \mathrm{P}_{\mathrm{Tie}}$ & \\
\hline Nominal & - & 3.72 & 4.03 & 5.79 & 0.5 & 1.1 & 1.2 & -12.0 & -13.3 & -0.2 & 0.2156 \\
\hline \multirow{2}{*}{$\begin{array}{l}\text { Loading } \\
\text { conditions }\end{array}$} & +25 & 3.88 & 4.05 & 5.95 & 0.4 & 1.0 & 1.2 & -12.0 & -13.2 & -0.2 & 0.2800 \\
\hline & -25 & 3.63 & 4.70 & 5.00 & 0.5 & 1.1 & 1.2 & -12.1 & -13.3 & -0.2 & 0.2667 \\
\hline \multirow[t]{2}{*}{$\mathrm{T}_{\mathrm{G}}$} & +25 & 3.82 & 3.98 & 5.65 & 0.7 & 1.0 & 1.3 & -12.1 & -13.4 & -0.2 & 0.2246 \\
\hline & -25 & 3.64 & 4.72 & 5.01 & 0.4 & 1.1 & 1.2 & -11.8 & -13.1 & -0.2 & 0.2660 \\
\hline \multirow[t]{2}{*}{$\mathrm{T}_{\mathrm{T}}$} & +25 & 4.52 & 4.62 & 5.03 & 1.3 & 1.2 & 1.3 & -12.3 & -13.5 & -0.2 & 0.2663 \\
\hline & -25 & 3.74 & 4.00 & 5.08 & 0.4 & 1.0 & 1.2 & -11.6 & -13.0 & -0.2 & 0.2146 \\
\hline \multirow[t]{2}{*}{$\mathrm{T}_{\mathrm{RH}}$} & +25 & 3.89 & 4.96 & 5.92 & 0.3 & 0.9 & 1.2 & -12.0 & -13.2 & -0.2 & 0.2756 \\
\hline & -25 & 3.06 & 4.69 & 5.31 & 0.7 & 0.7 & 1.2 & -12.1 & -13.3 & -0.2 & 0.2589 \\
\hline \multirow[t]{2}{*}{$T_{C D}$} & +25 & 3.89 & 5.04 & 5.72 & 0.5 & 0.9 & 1.2 & -12.0 & -13.3 & -0.2 & 0.2925 \\
\hline & -25 & 3.62 & 5.11 & 5.35 & 0.5 & 0.9 & 1.3 & -12.0 & -13.3 & -0.2 & 0.2797 \\
\hline \multirow[t]{2}{*}{$\mathrm{T}_{12}$} & +25 & 4.03 & 4.64 & 4.87 & 0.4 & 0.9 & 1.3 & -12.1 & -13.2 & -0.2 & 0.2560 \\
\hline & -25 & 3.85 & 4.08 & 5.22 & 0.6 & 1.1 & 1.1 & -11.9 & -13.4 & -0.3 & 0.2453 \\
\hline
\end{tabular}

adequately. The eigenvalues and damping ratio of the proposed approach (hDE-PS: FOPID; with HVDC link) is shown in Table 7. It is well known in control system that as long as the real part of complex eigenvalue is negative, then the system is stable. It is marked from Table 7 that all the eigenvalues lie in the left half of s-plane for the proposed approach, so preserve the stability.

\section{Comparison with recent AGC approaches}

The performance of the suggested AGC method also examined in an extensively utilized a non-reheat-type thermal system [7-11] is considered as presented in Fig. 2. Two 


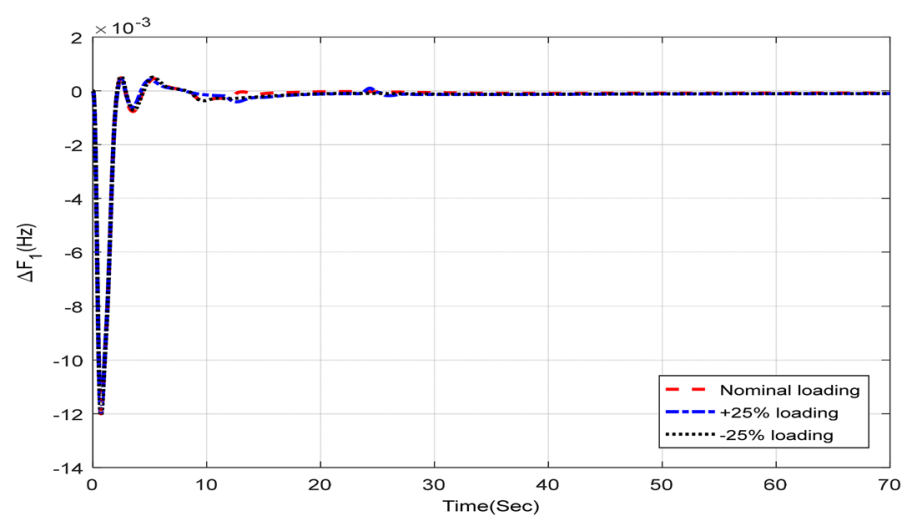

Fig. $8 \Delta \mathrm{F}_{1}$ for variation of loading
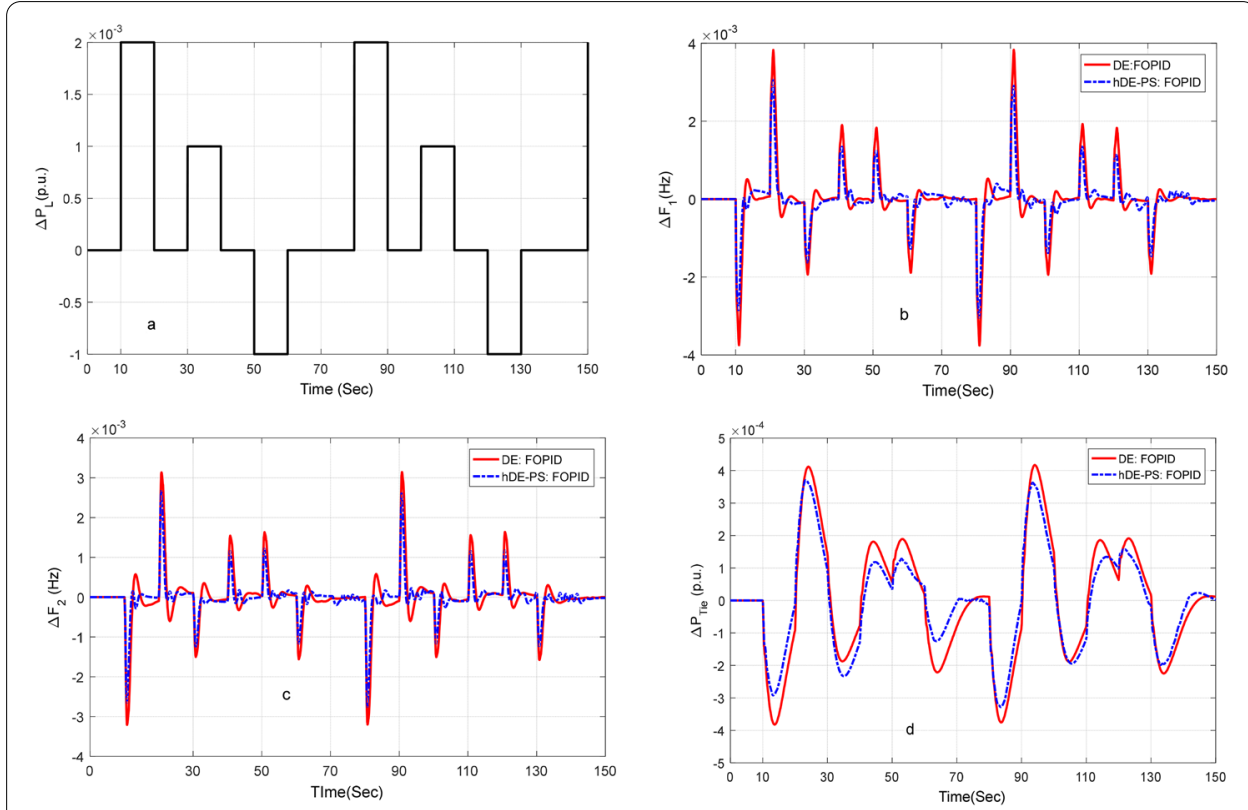

Fig. 9 a Step load random pattern $\mathbf{b} \Delta F_{1} \mathbf{c} \Delta F_{2} \mathbf{d} \Delta P_{\text {tie }}$

Table 7 Eigenvalues and minimum damping ratio (hDE-PS: FOPID; with HVDC link)

\begin{tabular}{|c|c|}
\hline System modes $\left(\times 10^{3}\right)$ & $\zeta$ \\
\hline $\begin{array}{l}-0.8578,-0.9999,-1.0,-0.6795,-0.6511,-0.527,-0.5191,-0.2947,-0.2443,-0.1935, \\
-0.1854,-0.1501,-0.1478, \\
-0.0839,-0.0696,-0.0552,-0.0528,-0.0427,-0.0421,-0.0239,-0.0204,-0.0158,-0.0151, \\
-0.0119,-0.0120 \pm 0.0001 i_{,} \\
-0.012,-0.0068,-0.0055 \pm 0.0006 \mathrm{i},-0.0055 \pm 0.0005 \mathrm{i},-0.0009 \pm 0.0030 \mathrm{i},-0.0025 \pm 0.0025 \mathrm{i}, \\
-0.0045,-0.0036,-0.0036 \pm 0.0005 \mathrm{i},-0.0034 \pm 0.0004 \mathrm{i},-0.005,-0.0027,-0.0034,-0.0050, \\
-0.0020 \pm 0.0001 \mathrm{i},-0.0020,-0.0016 \pm 0.0002 \mathrm{i}, \\
-0.0015,-0.0013,-0.0003 \pm 0.0005 \mathrm{i},-0.0013 \pm 0.0001 \mathrm{i},-0.0012,-0.0010,-0.0009,-0.0006, \\
-0.0005,-0.0004, \\
-0.0002 \pm 0.0001 \mathrm{i},-0.0003,-0.0002,-0.0001\end{array}$ & 0.2840 \\
\hline
\end{tabular}


identical PID/FOPID structures are taken for each area owing to their identical nature. A sudden rise in a load of $10 \%$ is applied in area- $1 \Delta P_{D 1}=0.01$ p.u.MW at $\mathrm{t}=0 \mathrm{~s}$, and gains of PID/ FOPID controller are found to be:

DE- PID: $K_{\mathrm{P}}=1.2425, K_{\mathrm{I}}=1.5984, K_{\mathrm{D}}=1.5443$.

DE- FOPID: $K_{\mathrm{P}}=1.9279, K_{\mathrm{I}}=1.9549, K_{\mathrm{D}}=1.2137, \lambda=0.9903, \mu=0.5806$.

Proposed hybrid DE-PS- FOPID: $K_{\mathrm{P}}=1.6482, K_{\mathrm{I}}=1.5386, K_{\mathrm{D}}=0.9325, \lambda=1.0032$, $\mu=1.1082$.

The performance of the suggested method (hDE-PS: FOPID) is equated by conventional as well as some new optimization method such as conventional $\mathrm{ZN}$ : PI [7], GA: PI [7], BFOA: PI [7, PSO: PI [7], hBFOA-PSO: PI [9], NSGA-II: PI [10] NSGA-II: PIDF [10], DE: PI [8], FA: PI [11] and FA: PID [11]. The ITAE values obtained with each approach are presented in Table 8 . It is seen from Table 8 that the lowest error value $(\mathrm{ITAE}=0.2527)$ is acquired by the suggested method (hDE-PS: FOPID) as compared to newly suggested AGC methods. The transient responses of the system are publicized in Fig. 10a-c from which it is apparent that the suggested method outperforms newly suggested automatic generation control methods.

\section{Conclusions}

In this manuscript, hDE-PS technique-based FOPID/PID/optimal controller has been suggested for control of frequency in electrical power system with/without HVDC link. Performance of the suggested approach is tested on two electrical power system models. Initially, a 2-area system with varied sources of generations like hydro, gas and thermal via parallel AC/DC link is considered. To make the system more sensible, time delay has been integrated into the model. The gains of FOPID are tuned using a hDE-PS method. The advantage of the suggested hDE-PS method over the DE technique has been verified. To confirm the supremacy of the suggested method (hDE-PS: FOPID), results are equated with DE-based optimal/PID/FOPID controller for the equal test system. It is recognized that the suggested method (hDE-PS: FOPID) provides better performance than others. Simulation results also show that with DC-link further progress the system performance with the suggested method. Further, sensitivity investigation is executed

Table 8 Comparison of various AGC approaches for a 2-area system

\begin{tabular}{lr}
\hline Performance/Technique: Control Structure & ITAE \\
\hline Conventional ZN: PI[7] & 3.7568 \\
GA:PI[7] & 2.7475 \\
BFOA: PI[7] & 1.8379 \\
PSO: PI [9] & 1.2142 \\
hBFOA-PSO: PI [9] & 1.1865 \\
NSGA-II: PI [10] & 1.1785 \\
NSGA-II: PIDF [10] & 0.3870 \\
DE: PI [8] & 0.9911 \\
FA:PI [11] & 0.8695 \\
FA:PID [11] & 0.4714 \\
DE: PID & 0.3678 \\
DE: FOPID & 0.3088 \\
Proposed hybrid DE-PS based FOPID & 0.2527 \\
\hline
\end{tabular}



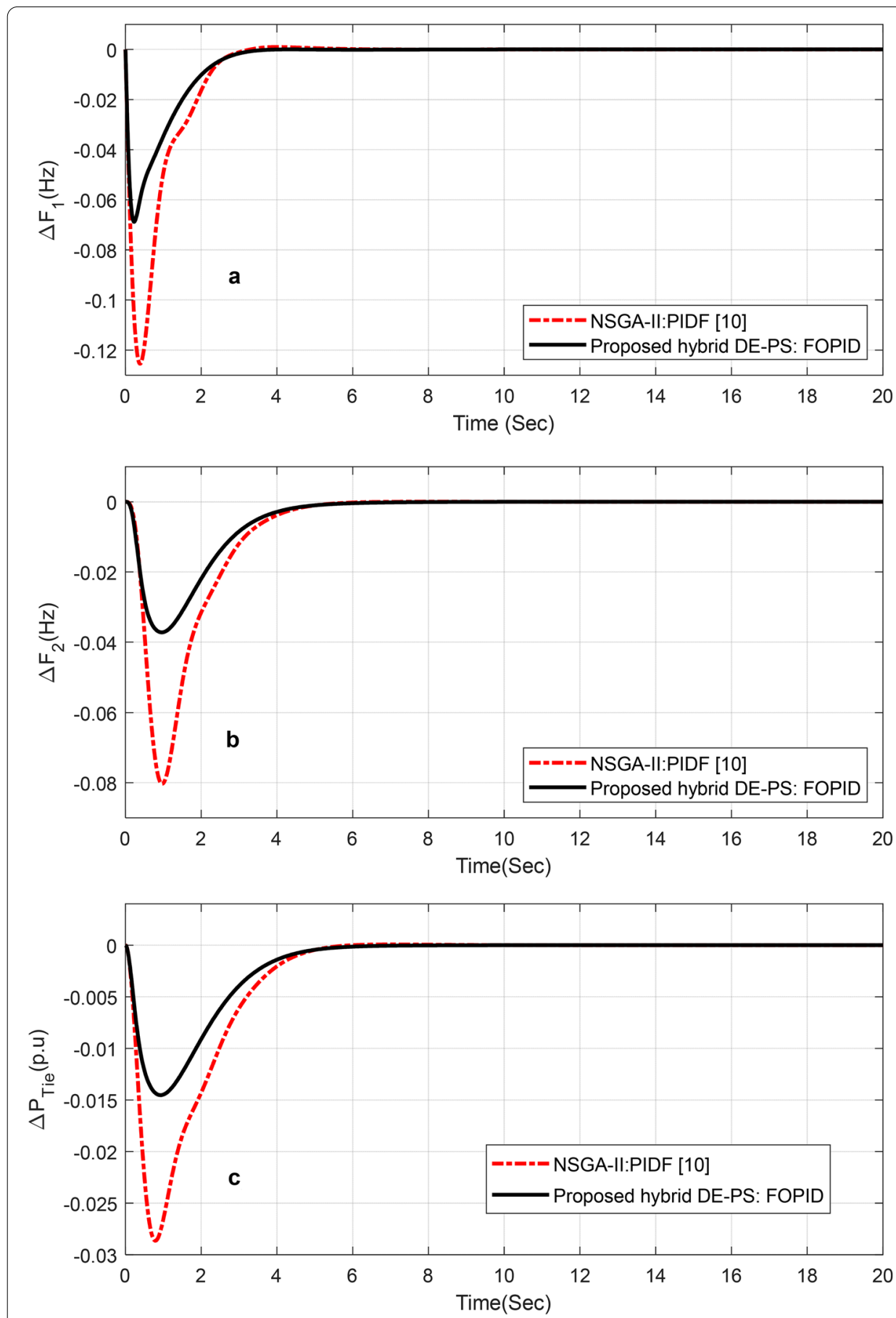

Fig. 10 System response for test system-II( $\Delta P_{D 1}=0.1$ p.u.MW\& $\left.\Delta P_{D 2}=0\right)$. a $\Delta \mathrm{F}_{1} \mathbf{b} \Delta \mathrm{F}_{2} \mathbf{c} \Delta \mathrm{P}_{\text {tie }}$

by changing the parameters and load conditions from their nominal values to show the strength of the suggested hybrid DE-PS algorithm-optimized FOPID. It was observed that the suggested method (hDE-PS: FOPID) is robust. Finally, the usefulness and robustness of the suggested scheme against random load variations were investigated. The performance of the suggested AGC method is also investigated in an extensively 


\section{exercised two-area system. It is noticed that the proposed method is superior to various newly suggested approaches.}

\section{Abbreviations}

LFC: Load frequency control; hDE-PS: Hybrid differential evolution and pattern search; PID : Proportional integral derivative controller; FOPID: Fractional-order proportional integral derivative; GA: Genetic algorithm; GWO: Grey wolf optimization; BFOA: Bacteria Foraging Optimization Algorithm; DE: Differential Evolution; PSO: Particle Swarm Optimization; FA: Firefly Algorithm; ICA: Imperialist Competitive Algorithm; TD: Time delay; $F$ : Nominal system frequency; $\Delta F$ : Frequency deviation; $\Delta P_{D}$ : Incremental step load change; $t_{\text {sim }}$ : Simulation time.

\section{Acknowledgements}

Not applicable.

\section{Authors' contributions}

PCP carried out the literature survey and proposed hybrid differential evolution and pattern search technique for frequency regulation of the current study. RKS has written the manuscript and submitted the paper to journal. SP contributed in designing of fractional-order proportional integral derivative (FOPID) controller and performed the simulation studies. All authors read and approved the final manuscript.

\section{Funding}

Not applicable.

\section{Availability of data and materials}

The data used in this research are well referred by the authors in manuscript.

\section{Declaration}

\section{Competing interests}

The authors declare that they have no competing interests.

\section{Author details}

'Department of Electrical Engineering, DRIEMS, Cuttack, Odisha 754 022, India. ${ }^{2}$ Department of Electrical \& Electronics Engineering, Veer Surendra Sai University of Technology (VSSUT), Burla, Odisha 768018, India. ${ }^{3}$ Department of Electrical Engineering, Veer Surendra Sai University of Technology (VSSUT), Burla, Odisha 768018, India.

Received: 17 July 2020 Accepted: 10 March 2021

Published online: 01 April 2021

\section{References}

1. Elgerd OI (2000) Electric energy systems theory an introduction. Tata McGraw Hill, New Delhi

2. Bevrani H (2009) Robust power system frequency control. Springer

3. Pandey SK, Mohanty SR, Kishor N (2013) A literature survey on load-frequency control for conventional and distribution generation power systems. Renew Sustain Energy Rev 25:318-334

4. Shayeghi $\mathrm{H}$, Shayanfar HA, Jalili A (2009) Load frequency control strategies: a state-of-the art survey for the researcher. Energy Convers Manag 50(2):344-353

5. Hassan HA, Mohamad EHG, Reza Z, Ehsan HF, Pierluigi S (2018) Challenges and opportunities of load frequency control in conventional, modern and future smart power systems: a comprehensive review. Energies 11:1-35

6. Ibraheem KP, Kothari DP (2005) Recent philosophies of automatic generation control strategies in power systems. IEEE Trans Power Syst 20:346-357

7. Ali ES, Abd-Elazim SM (2011) Bacteria foraging optimization algorithm based load frequency controller for interconnected power system. Int J Electr Power Energy Syst 33(3):633-638

8. Rout UK, Sahu RK, Panda S (2013) Design and analysis of differential evolution algorithm based automatic generation control for interconnected power system. Ain Shams Eng J 4(3):409-421

9. Panda S, Mohanty B, Hota PK (2013) Hybrid BFOA-PSO algorithm for automatic generation control of linear and nonlinear interconnected power systems. Appl Soft Comput 13(12):4718-4730

10. Panda S, Yegireddy NK (2013) Automatic generation control of multi-area power system using multi-objective nondominated sorting genetic algorithm-II. Int J Elect Power Energy Syst 53:54-63

11. Padhan S, Sahu RK, Panda S (2014) Application of firefly algorithm for load frequency control of multi-area interconnected power system. Electr Power Compo Syst 42(13):1419-1430

12. Gozde H, Taplamacioglu MC (2011) Automatic generation control application with craziness based particle swarm optimization in a thermal power system. Int J Elect Power Energy Syst 33:8-16

13. Sahu RK, Panda S, Rout UK, Sahoo DK (2016) Teaching learning based optimization algorithm for automatic generation control of power system using 2-DOF PID controller. Int J Electr Power Energy Syst 77:287-301

14. Sahu RK, Panda S, Padhan S (2014) Optimal gravitational search algorithm for automatic generation control of interconnected power systems. Ain Shams Eng J 5:721-733

15. Jagatheesan K, Anand B, Samanta S, Dey N, Santhi V, Ashour AS, Balas VE (2017) Application of flower pollination algorithm in load frequency control of multi-area interconnected power system with nonlinearity. Neural Comput Appl 28(1):475-488 
16. Guha D, Roy PK, Banerjee S (2016) Load frequency control of interconnected power system using grey wolf optimization. Swarm Evol Comput 27:97-115

17. Shabani H, Vahidi B, Ebrahimpour M (2012) A robust PID controller based on imperialist competitive algorithm for load-frequency control of power systems. ISA Trans 52:88-95

18. Sivalingam R, Chinnamuthu S, Dash SS (2017) A hybrid stochastic fractal search and local unimodal sampling based multistage PDF plus (1 + PI) controller for automatic generation control of power systems. J Frankl Inst 354(12):4762-4783

19. Chintu JM, Sahu RK, Panda S (2019) Adaptive differential evolution tuned hybrid fuzzy PD-PI controller for automatic generation control of power systems. Int J Ambient Energy 17:1-6

20. Mohanty P, Sahu RK, Panda S (2020) A novel hybrid many optimizing liaisons gravitational search algorithm approach for AGC of power systems. Automatika 61(1):158-178

21. Acharyulu BVS, Mohanty B, Hota PK (2020) Analysis of moth flame optimization optimized cascade proportionalintegral-proportional-derivative controller with filter for automatic generation control system incorporating solar thermal power plant. Optim Control Appl Methods. https://doi.org/10.1002/oca.2582

22. Sahu RK, Panda S, Padhan S (2015) A novel hybrid gravitational search and pattern search algorithm for load frequency control of nonlinear power system. Appl Soft Comput 29:310-327

23. Khamari D, Sahu RK, Panda S (2020) A modified moth swarm algorithm based hybrid fuzzy PD-PI controller for frequency regulation of distributed power generation system with electric vehicle. J Control Autom Electr Syst. https:// doi.org/10.1007/s40313-020-00565-0

24. Mohanty B, Panda S, Hota PK (2014) Controller parameters tuning of differential evolution algorithm and its application to load frequency control of multi-source power system. Int J Elect Power \& Energy Syst 54:77-85

25. Parmar KPS, Majhi S, Kothari DP (2012) Improvement of dynamic performance of LFC of the two area power system: an analysis using MATLAB. Int J Comp Appl 40:28-32

26. Parmar KPS, Majhi S, Kothari DP (2012) Load frequency control of a realistic power system with multi-source power generation. Int J Elect Power Energy Syst 42:426-433

27. Ibraheem N, Bhatti TS (2014) AGC of two area power system interconnected by AC/DC links with diverse sources in each area. Int J Elect Power Energy Syst 55:297-304

28. Saikia LC, Nanda J, Mishra S (2011) Performance comparison of several classical controllers in AGC for multi-area interconnected thermal system. Int J Elect Power Energy Syst 33:394-411

29. Sahu RK, Panda S, Rout UK (2013) DE optimized parallel 2-DOF PID controller for load frequency control of power system with governor dead-band nonlinearity. Int J Electr Power Energy Syst 49(1):19-33

30. Mohanty B (2015) TLBO optimized sliding mode controller for multi-area multi-source nonlinear interconnected AGC system. Int J Electr Power Energy Syst 73:872-881

31. Sahu RK, Panda S, Biswal A, Sekhar GTC (2016) Design and analysis of tilt integral derivative controller with filter for load frequency control of multi-area interconnected power systems. ISA Trans 61:251-264

32. Saha A, Saikia LC (2018) Combined application of redox flow battery and DC link in restructured AGC system in the presence of WTS and DSTS in distributed generation unit. IET Gener Transm Distrib 12(9):2072-2085

33. Arya Y (2019) A new optimized fuzzy FOPI-FOPD controller for automatic generation control of electric power systems. J Frankl Inst 356:5611-5629

34. Arya Y (2018) Improvement in automatic generation control of two-area electric power systems via a new fuzzy aided optimal PIDN-FOI controller. ISA Trans 80:475-490

35. Elyas R (2013) Intelligent linear-quadratic optimal output feedback regulator for a deregulated automatic generation control system. Electr Power Comp Syst 40(5):513-533

36. Ibraheem PK, Hasan N, Nizamuddin (2012) Sub-optimal automatic generation control of interconnected power system using output vector feedback control strategy. Elect Power Comp Syst 40(9):977-994

37. Aboelela MAS, Ahmed MFD, HT (2012) Design of aerospace control systems using fractional PID controller. Adv Res 3(3):225-232

38. Dolan ED, Lewis RM, Torczon V (2013) On the local convergence of pattern search. SIAM J Optim 14(2):567-583

39. Panda S (2011) Differential evolution algorithm for SSSC-based damping controller design considering time delay. J Frankl Inst 348(8):1903-1926

40. Stron R, Price K (1995) Differential evolution: a simple and efficient adaptive scheme for global optimization over continuous spaces. J Glob Optim 11:341-359

\section{Publisher's Note}

Springer Nature remains neutral with regard to jurisdictional claims in published maps and institutional affiliations. 